\title{
Chest Irradiation Associated Cardio-Vascular Disease
}

\author{
Malka Yahalom¹, Ehud Rozner1, Menachem Nahir'1, Lev Bloch1, Yoav Turgeman1,2* \\ ${ }^{1}$ Heart Institute, HaEmek Medical Center, Afula, Israel \\ ${ }^{2}$ Rappaport Faculty of Medicine, Technion, Haifa, Israel \\ Email: *Yoav_t@clalit.org.il
}

Received 15 November 2015; accepted 26 June 2016; published 29 June 2016

Copyright (C) 2016 by authors and Scientific Research Publishing Inc.

This work is licensed under the Creative Commons Attribution International License (CC BY).

http://creativecommons.org/licenses/by/4.0/

(c) (i) Open Access

\begin{abstract}
Background: The heart and great vessels were once thought to be relatively resistant to the damaging effect of radiation therapy. There is now clear evidence that thoracic irradiation may cause acute inflammation and progressive fibrosis of different structures, including the heart valves, the myocardium and the pericardium, the coronary arteries and the conduction system. As new therapies have improved survival, many patients with cancer (mostly Hodgkin's disease and breast cancer) are now at risk of cardiovascular (CV) complications following radiation therapy. Objectives: To raise awareness of CV complications following chest irradiation. Method: We present 5 patients that we treated during a short period of time (between June $2013(6 / 2013)$ and February 2015 (2/2016)), who suffered CV involvement that needed therapy, following chest irradiation. Conclusions: Patients after chest irradiation should be followed periodically, in order to diagnose and treat CV complications, in time.
\end{abstract}

\section{Keywords}

Chest Irradiation, Cardiovascular Involvement

\section{Introduction}

The heart and great vessels were once thought to be relatively resistant to the damaging effects of radiation therapy. There is now clear evidence that thoracic irradiation may cause inflammation and progressive fibrosis of different thoracic structures, including the heart valves, the myocardium, the pericardium, the coronary arteries, and also the conduction system [1]-[9].

Although radiotherapy is not the sole or only causative factor, in all cases, for rapid calcification of blood

\footnotetext{
"Corresponding author.
} 
vessels and cardiotoxicity, it is no doubt an accelerating factor.

As new therapies have improved survival, many patients with cancer (mostly Hodgkin's disease and breastcancer) are now at risk of cardiovascular (CV) complications after radiation therapy.

It has been shown that among Hodgkin's lymphoma and breast cancer patients, treated with radiotherapy, cardiovascular disease (CVD) is the most common malignant cause of death; and over the long term, the benefits of radiotherapy might be partially offset by cardiac complications.

Multiple studies have shown that radiation induced cardiac disease encompasses a wide spectrum of deleterious effects on the heart, from pre-clinical histopathological findings to symptomatic clinical disease, including: coronary artery disease, valvular heart disease (mainly left (high pressure) side) [1], and mostly valvular insufficiency, also pericardial disease, autonomic dysfunction and sudden death.

It has been shown that the higher incidence of late effects of cardiac complications is related to factors such as: the (younger) age at the time of thoracic irradiation; topography, left-sided vs. right sided irradiation [5]; coexistence of adjuvant chemotherapy, as well as the longer time that had elapsed since radiation therapy ("the time and era of the old radiation therapy protocols") [4] and the existence of the risk factors of CAD [6]. It was emphasized that one should be careful before drawing any conclusions concerning the effectiveness of the modern irradiation therapy methods, such as "breath holding techniques" during therapy in reducing cardiac toxicity; because older trials, which have reported excess cardiac toxicity, were dealing with a much longer follow-up duration [10].

It has been shown that the sequels of chest irradiation were: pericardial thickening, pericardial effusion, constrictive pericarditis, valves cusp-leaflet fibrosis (with or without calcification), marked chordal thickening and fusion (mostly left-side valves (Mitral and Aortic)), presented with valve insufficiency and less stenosis; and myocardial and coronary arteries fibrosis.

Our purpose was to raise awareness of CV complications following chest irradiation.

\section{Method}

We present data obtained through medical history, during the index event, from 5 patients who had suffered from cardiovascular complications following chest irradiation.

First Case: A 42-year-old male was presented with dizziness and second degree (2:1) Atrio-Ventricular (AV) block, two years post Coronary-Artery Bypass Graft (CABG) surgery. 25 years earlier, the patient had been treated with radiotherapy to the mediastinum for lymphoma. A chest CT revealed calcification of the 3 coronary arteries, the aortic root, aortic valve and Mitral annulus (Figure 1).

The patient was treated with a permanent pacemaker.

Second Case: A 60-year-old female, who was treated at childhood by radiation therapy to her upper chest and neck, for cervical neuroblastoma, presented with dyspnea at effort, for the past 10 years, with the clinical and

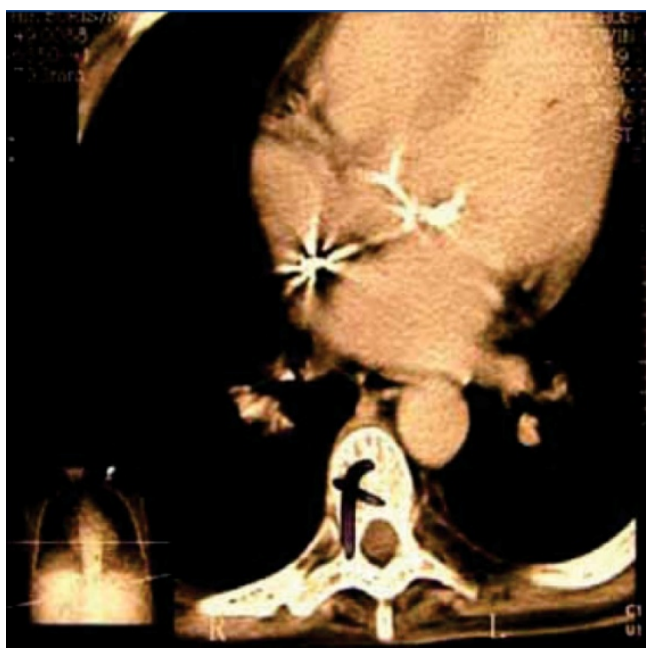

Figure 1. Chest CT demonstrating calcification of mitral annulus and of the coronary arteries. 
laboratory evidence of severe pulmonic stenosis (Figure 2), with peak Systolic Pressure Gradient (PG) of 70 mmHg, and documented patent coronary arteries (Figure 3; Figure 4). The patient was successfully treated by pulmonic balloon valvuloplasty, followed recently by percutaneous Pulmonic Valve Implantation.

Third Case: A 56-year-old female, known with hyperlipidemia and a family history of IHD, who was treated two years earlier by left chest irradiation for breast cancer, had complained of effort angina and had a positive Exercise Test.

On heart catheterization there was evidence of two-vessel disease-successfully treated by PCI (Figure 5; Figure 6).

Forth Case: A 43-year-old female, known to suffer from Diabetes-Mellitus and Hyperlipidemia, was treated in 1996 by radiotherapy to the mediastinum for Hodgkin's Lymphoma. During 2012-2014 the patient passed 4 coronary angioplasty because of angina pains, during which stents were implanted in the Left Main (LM) and Right Coronary Artery (RCA). Moderate Aortic Valve stenosis (of 45 mm Hg gradient) was diagnosed (Figure 7).

Fifth Case: A 64-year-old female, known with Juvenile Diabetes, peripheral vascular disease and renal failure, was presented a few months ago with sudden fatigue, slow heart rate (Atrio-ventricular (AV) block with ventricular rate of less than 30 beats/min) (Figure 8) treated with a temporary pacemaker, and later by a permanent CRTD (defibrillator) implantation (Figure 9). The patient was treated 10 years earlier for left breast cancer, by lumpectomy, chemotherapy and chest irradiation, followed by congestive heart failure (LVEF $=25 \%$ ).

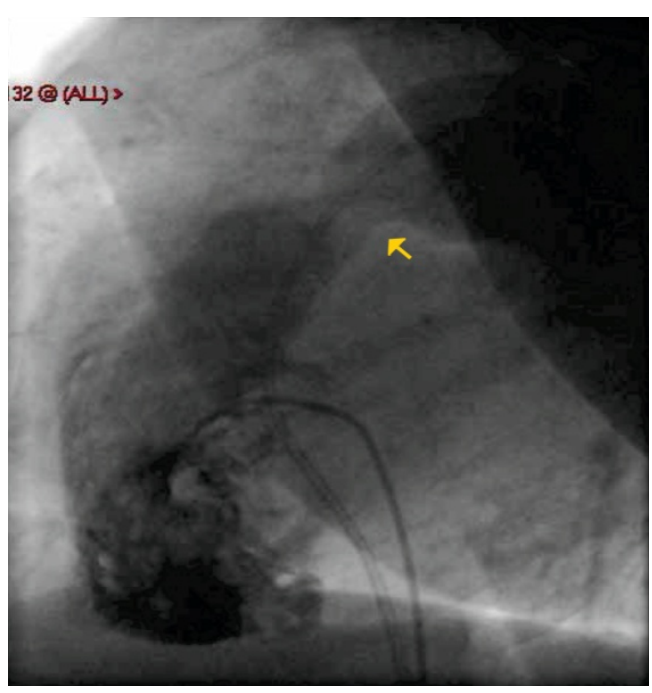

Figure 2. (Case 2): Pulmonic stenosis.

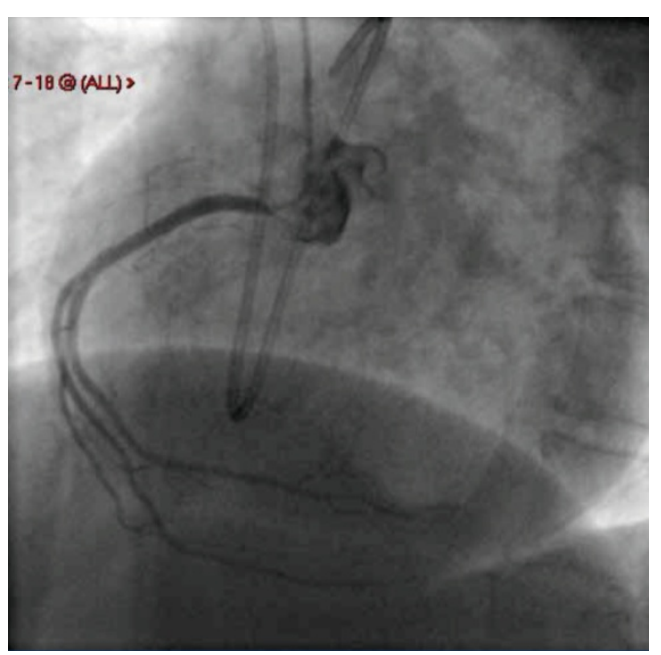

Figure 3. (Case 2): Patent RCA. 


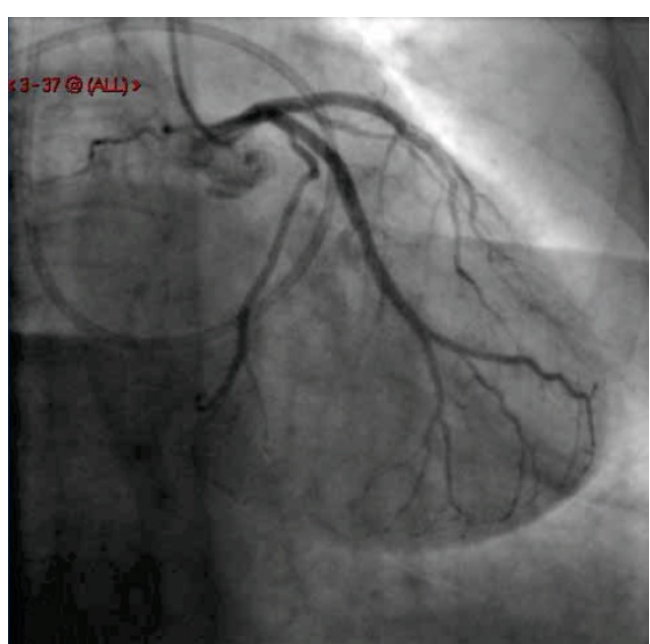

Figure 4. (Case 2): Left coronary artery system.

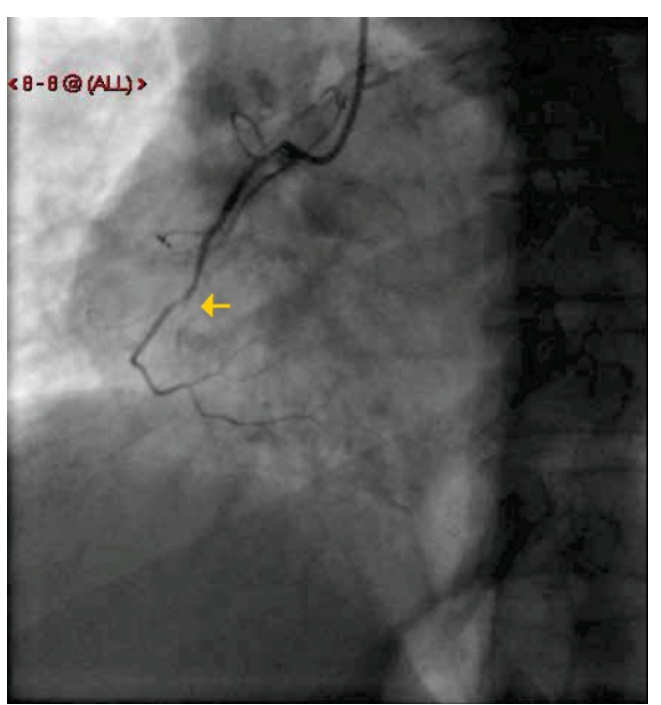

Figure 5. (Case 3): RCA.

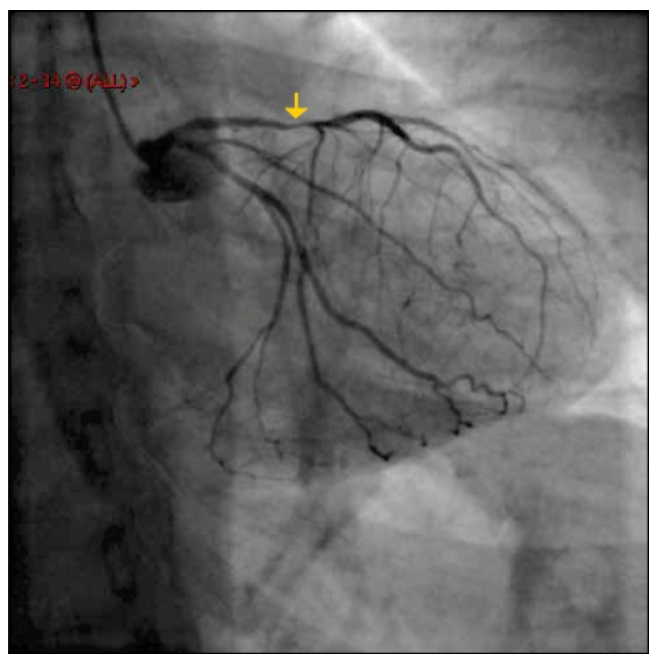

Figure 6. (Case 3): Lt. coronary artery system. 


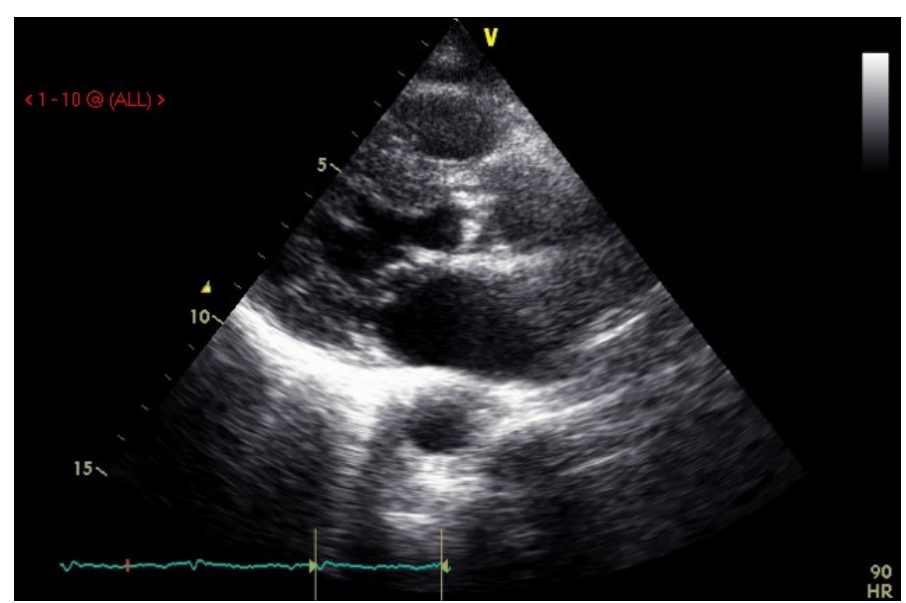

(a)

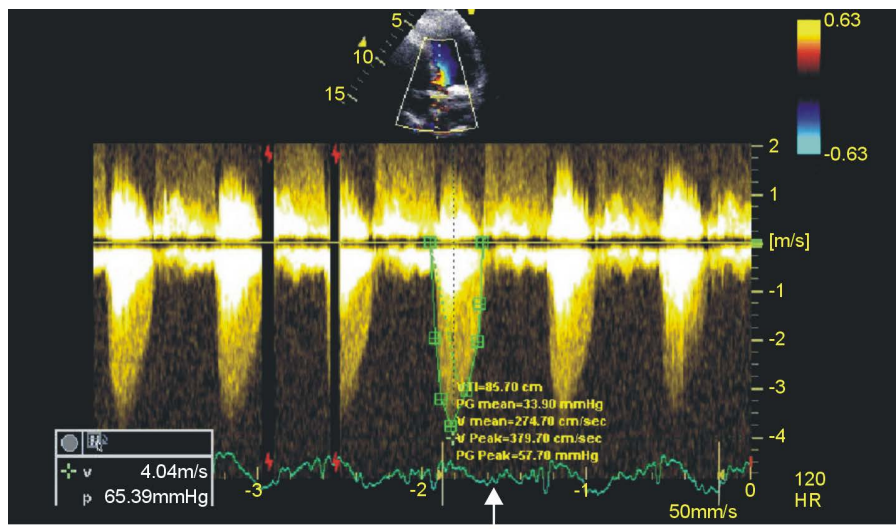

VTI-Velocity Time Integral $=85.70 \mathrm{~cm}$

PG mean-Pressure Gradient mean $=33.90 \mathrm{mmHg}$

$V$ mean-Velocity mean $=274.70 \mathrm{~cm} / \mathrm{sec}$

$\mathrm{V}$ peak $=$ Velocity peak $=379.70 \mathrm{~cm} / \mathrm{sec}$

PG Peak-Pressure Gradient Peak $=57.70 \mathrm{mmHg}$

(b)

Figure 7. (Case 4): (a) M-model echocardiography-calcified aortic stenosis; (b) Aortic stenosis and pressure gradient.

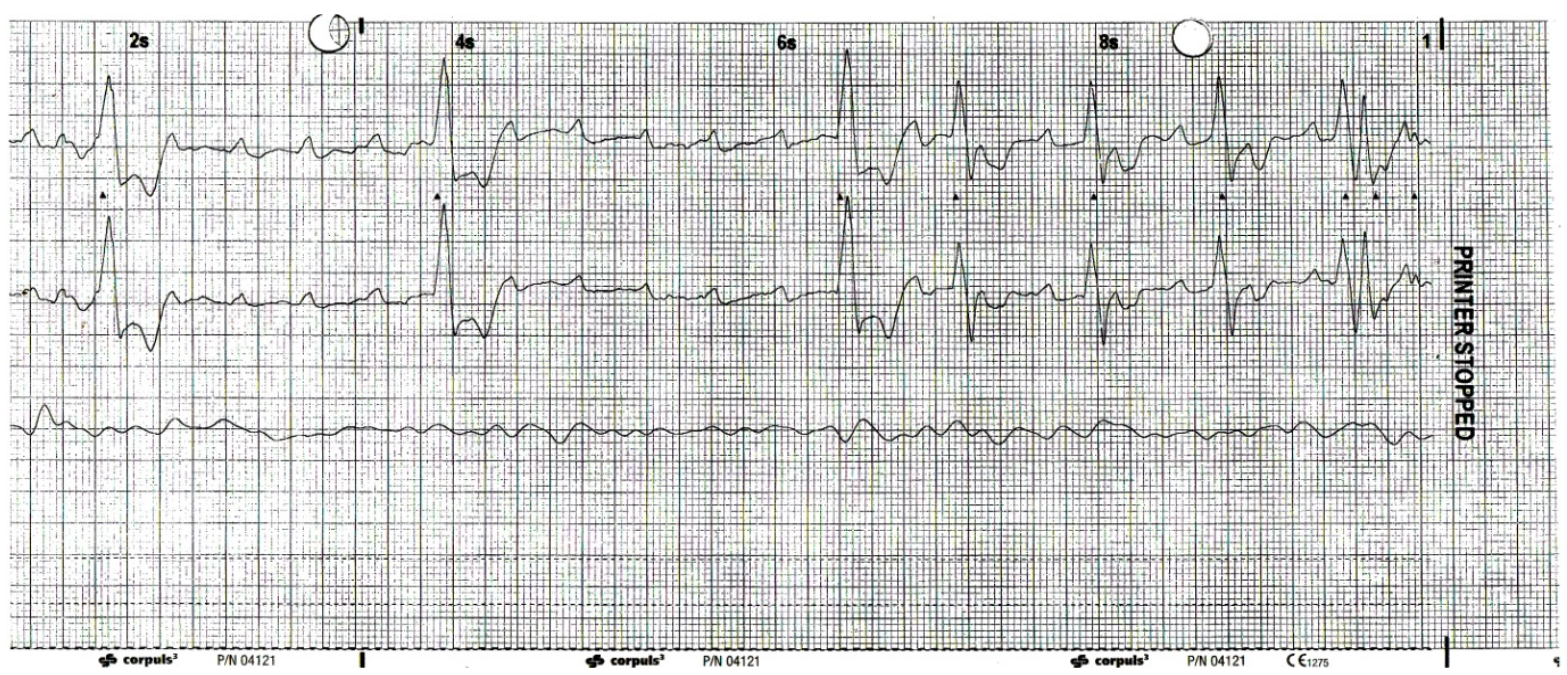

Figure 8. (Case 5): Atrio-ventricular block. 


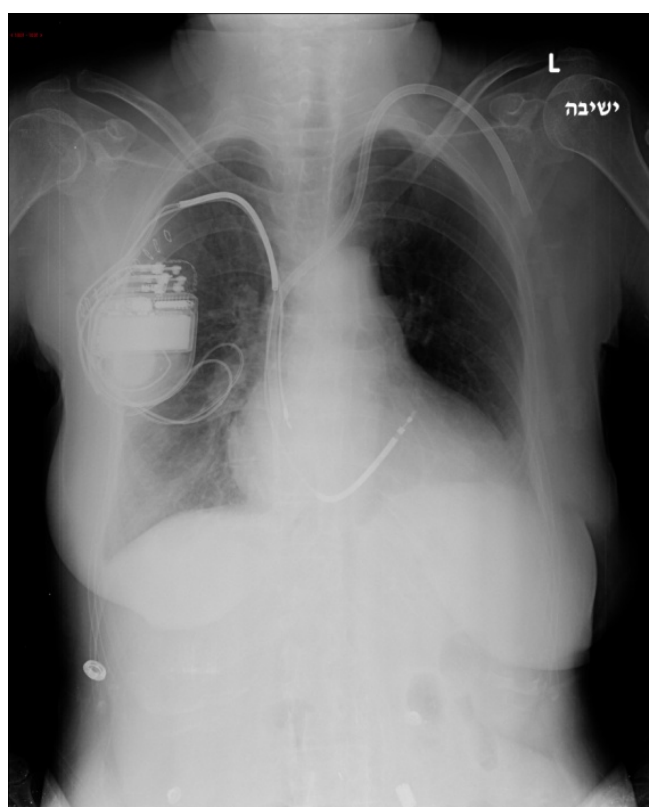

Figure 9. (Case 5): Chest X-ray and permanent CRTD.

In Summary: Thus, during a short period of time (less than two years), we met 5 patients who suffered cardiovascular toxicity following chest irradiation therapy.

\section{Discussion}

The prevalence of radiation associated cardiac disease is increasing, due to the prolonged survival following mediastinal irradiation. It has been shown that the side effects of radiation therapy include: pericarditis, accelerated coronary disease, myocardial fibrosis, valvular and heart conduction system injury, central and peripheral arteries calcification and stenosis. These conditions often required surgical or percutaneous interventions, and often presented years and decades after radiation therapy [11]-[23]. This is especially so when radiation therapy was combined with adjuvant therapy [24].

The pathology and pathogenesis of radiation induced heart disease has been studied in the last four decades in patients in whom cardiac-tissue, that exhibited radiation related injury, was available (surgical or at autopsy) [25] [26], as well as in animal models [27].

It has been shown [10] that the mechanism of radiation-induced myocardial fibrosis is the sequel of damage to the endothelial cells of blood capillaries, which vary from luminal projections of cytoplasm - to cell necrosis, with rapture of the capillary wall. Platelets and fibrin thrombi were the prominent features of injured capillaries, seen in the early "silent" clinical period. Later, after 70 days, the ultra-structural lesions were less prominent, but there was marked reduction in the number of capillaries, and concomitant progressive fibrosis.

The compensatory mechanism of endothelial cell renewal was inadequate to construct the damaged capillaries' network; and thus, the insufficient microcirculation finally lead to diffuse myocardial fibrosis [10]. It has also been emphasized that the non-dividing myocytes are relatively resistant to the direct harmful radiation effect; and the damage to the myocardium leading to myocardial-fibrosis—is indirect—via the lowering number of available capillaries and blood vessels that supply blood, oxygen, glucose, etc.

The first reported case of radiation-induced heart disease with compared image views operative findings and pathological findings was reported by Domoto et al. in 2014 [28].

We have described 5 patients, who suffered cardiovascular involvement after chest radiation therapy, who we had met and treated between June 2013 (6/2013) and February 2015 (2/2016). The first one was treated in his youth with chemotherapy and radiotherapy to the mediastinum, for Hodgkin's Lymphoma, and treated again, a generation later, by a coronary artery bypass graft (GABG) operation and by permanent pacemaker therapy.

Santoro et al. described in 2012 a case of a 44-year-old man with history of Hodgkin lymphoma, treated with 
chemo- and radio-therapy 6 years earlier, who presented with episodes of syncope and complete AV block and needed pacemaker therapy implantation [29].

Two years later, Trapani et al. described a 47-year-old female patient with no history of cardiac disease, who presented with recurrent syncope, high degree AV Block, treated with temporary and permanent pacemaker implantation. The patient had a history of left breast cancer, treated with chemotherapy and radiotherapy 13 years earlier, with regular follow-up for many years. The conduction disturbances were attributed to the radiotherapy [30].

Our second case was a female patient who was treated in her childhood by irradiation therapy to her upper chest and neck, for cervical neuroblastoma; through the patient's medical history, it was established that cardiac systolic murmur or data indicating congenital pulmonic stenosis were not mentioned or recorded until the age of 12. Two generations later, echocardiographic data did not show doming or dysplasia of pulmonic valve, but showed heavy calcification that was successfully treated by pulmonic balloon valvuloplasty, for severe pulmonic valve stenosis. We presume, and cannot rule out, that the extensive fibrosis and calcification of the valve was due to the radiation therapy.

Velebit et al. have described Right Ventricular outflow obstruction after radiation therapy [13]. Pure infundibular pulmonary stenosis induced by radiation therapy was also described by Ratayama et al. in 1988 [14].

The third patient in our study was treated successfully by percutaneous coronary intervention for symptomatic two vessel disease, two years after left chest radiation for breast cancer, which initiated or aggravated her coronary artery disease (CAD).

The forth patient presented with CAD and Aortic Valve Stenosis. This is similar to cases Tamura et al. reported in 2007, of four patients who underwent mediastinal radiotherapy for malignancy almost a generation earlier — who all suffered from Aortic Stenosis and required valvular operations [31].

Finally, our fifth patient presented with symptomatic high degree AV Block that needed permanent pacemaker therapy.

It is emphasized in many clinical and experimental studies and publications [25] [26] that time elapsing between the radiation insult and the symptomatic cardiovascular disease, can take years and even decades. It was recommended that patients who were previously treated by chest irradiation should be followed clinically and by electrocardiography, especially when other risk factors for CAD exist [6]. It was also suggested that because of the high prevalence of asymptomatic heart disease following mediastinal irradiation, annual screening echocardiography should be considered after irradiation, in the same way that it is carried out following chemotherapeutic-adjuvant therapy [24].

\section{Conclusion}

Patients, after chest irradiation, should be followed periodically in order to diagnose and treat CV complications, in time.

\section{Acknowledgements}

To Mrs. Judy Pezaro; Mrs. Alla Polivoy; and Mr. Ori Bar-Am (X-Ray technician) for their great help and support.

\section{References}

[1] Adams, J., Hardenbergh, P.H., Constine, L.S. and Lipshultz, S.E. (2003) Radiation-Associated Cardiovascular Disease. Critical Reviews in Oncology/Hematology, 45, 55-75. http://dx.doi.org/10.1016/S1040-8428(01)00227-X

[2] Jaworski, C., Mariani, J.A., Wheeler, G. and Kaye, D.M. (2013) Cardiac Complications of Thoracic Irradiation. JACC, 61, 2319-2328. http://dx.doi.org/10.1016/j.jacc.2013.01.090

[3] Byrd, B.F. and Mendes, L.A. (2003) Cardiac Complications of Mediastinal Radiotherapy (Editorial Comments). JACC, 42, 750-751. http://dx.doi.org/10.1016/S0735-1097(03)00760-5

[4] Lepor, N.E. and Nassir, Y. (2014) Thoracic Irradiation-Evaluation of Long-Term Cardiovascular Effects. Reviews in Cardiovascular Medicine, 15, 71-73.

[5] Candeace, R., Correa, H.I., Litt, W.-T.H., Ferrari, V.A., Solin, L.J. and Harris, E.E. (2007) Coronary Artery Findings after Left-Sided Compared with Right-Sided Radiation Treatment for Early-Stage Breast Cancer. Journal of Clinical 
Oncology, 25, 3031-3037. http://dx.doi.org/10.1200/JCO.2006.08.6595

[6] Darby, S.C., Ewertz, M., McGale, P., Bennet, A.M., Bloom-Goldman, U., et al. (2013) Risk of Ischemic Heart Disease in Women after Radiotherapy for Breast Cancer. New England Journal of Medicine, 368, 987-998. http://dx.doi.org/10.1056/NEJMoa1209825

[7] Zagar, T.M. and Marks, L.B. (2013) Breast Cancer: Risk of Heart Disease after Radiotherapy-Cause for Concern. Nature Reviews Clinical Oncology, 10, 310-312. http://dx.doi.org/10.1038/nrclinonc.2013.59

[8] Mesurolle, B., Quandli, S.D., Merad, M., Mignon, F., Baldeyrou, P., et al. (2000) Unusual Radiologic Findings in the Thorax after Radiation Therapy. Radiographics, 20, 67-81. http://dx.doi.org/10.1148/radiographics.20.1.g00ja1167

[9] Carver, J.R., Shapiro, C.L., Ng, A., Jacobs, L., Schwartz, C., et al. (2007) American Society of Clinical Oncology Clinical Evidence Review on the Ongoing Care of Adult Cancer Survivors: Cardiac and Pulmonary Late Effects. Journal of Clinical Oncology, 25, 3991-4008. http://dx.doi.org/10.1200/JCO.2007.10.9777

[10] Demirci, S., Nam, J., Hubbs, J.L., Nguyen, T. and Marks, L.B. (2009) Radiation-Induced Cardiac Toxicity after Therapy for Breast Cancer: Interaction between Treatment Era and Follow-Up Duration. Journal of Radiation Oncology, Biology, Physics, 73, 980-987. http://dx.doi.org/10.1016/j.ijrobp.2008.11.016

[11] Carlson, R.G., Mayfield, W.R., Norman, S. and Alexander, J.A. (1991) Radiation-Associated Valvular Disease. Chest, 99, 538-545. http://dx.doi.org/10.1378/chest.99.3.538

[12] Tamura, A., Takahara, Y., Mogi, K. and Katsumata, M. (2007) Radiation-Induced Valvular Disease Is the Logical Consequence of Irradiation. General Thoracic and Cardiovascular Surgery, 55, 53-56. http://dx.doi.org/10.1007/s11748-006-0070-x

[13] Velebit, V., Van Segesser, L., Gabathuler, J., Jornod, J. and Faidutti, B. (1986) Right Ventricular Outflow Obstruction after Radiation Therapy. The Journal of Thoracic and Cardiovascular Surgery, 92, 153-161.

[14] Katayama, T., Irita, A. and Honda, Y. (1988) Pure Infundibular Pulmonary Stenosis Induced by Radiation Therapy-A Case Report. Angiology, 39, 843-848. http://dx.doi.org/10.1177/000331978803900909

[15] Ichinose, T., Nakazato, Y., Miyano, H., Kimura, T., Yamashita, H., et al. (2005) Severe Infundibular Pulmonary Stenosis and Coronary Artery Stenosis with Ventricular Tachycardia 24 Years after Mediastinal Irradiation. Internal Medicine, 44, 963-966.

[16] Bruhl, S.R., Sheikh, M., Adlakha, S., Khouri, S.Y. and Pandya, V. (2012) Endovascular Therapy for Radiation-Induced Pulmonary Artery Stenosis: A Case Report and Review of the Literature. Heart and Lung, 41, 87-89. http://dx.doi.org/10.1016/j.hrtlng.2010.11.004

[17] Latib, A., Montorfano, M., Figini, F., Maisano, F., Chieffo, A., et al. (2012) Percutaneous Valve Replacement in a Young Adult for Radiation-Induced Aortic Stenosis. Journal of Cardiovascular Medicine, 13, 397-398. http://dx.doi.org/10.2459/JCM.0b013e3283517c4a

[18] Veeragandham, R.S. and Goldin, M.D. (1998) Surgical Management of Radiation-Induced Heart Disease. The Annals of Thoracic Surgery, 65, 1014-1019. http://dx.doi.org/10.1016/S0003-4975(98)00082-4

[19] Jahangiri, M., Edmondson, S.J. and Rees, G.M. (1995) Surgery for Radiation-Induced Valvular Disease. The Journal of Heart Valve Disease, 4, 288-290.

[20] Choi, J.I., Pak, H.N. and Kim, Y.H. (2008) Recurrent Syncope 20 Years after Mediastinal Radiation Therapy in a Patient with Breast Cancer. Circulation Journal, 72, 1550-1552. http://dx.doi.org/10.1253/circj.CJ-07-0892

[21] Hull, M.C., Morris, C.G., Pepine, C.J. and Mendenhall, N.P. (2003) Valvular Dysfunction and Carotid, Subclavian, and Coronary Artery Disease in Survivors of Hodgkin Lymphoma Treated with Radiation Therapy. JAMA, 290, 28312837. http://dx.doi.org/10.1001/jama.290.21.2831

[22] Nilsson, G., Holmberg, L., Garmo, H., Duvernoy, O., Sjögren, I., Lagerqvist, B. and Blomqvist, C. (2012) Distribution of Coronary Artery Stenosis After Radition for Breast Cancer. Journal of Clinical Oncology, 30, 380-386. http://dx.doi.org/10.1200/JCO.2011.34.5900

[23] Zagar, T.M. and Marks, L.B. (2011) Breast Cancer Radiotherapy and Coronary and Coronary Artery Stenosis: Location, Location, Location (Editorial). Journal of Clinical Oncology, 30, 350-352. http://dx.doi.org/10.1200/JCO.2011.38.9304

[24] Elme, A., Saarto, T., Totterman, K.J., Utrianen, M., Kautianen, H., et al. (2013) Electrocardiography Changes during Adjuvant Breast Cancer Therapy: Incidence and Risk Factors. Anticancer Research, 33, 4933-4940.

[25] Veinot, J.P. and Edwards, W.D. (1996) Pathology of Radiation-Induced Heart Disease; A Surgical and Autopsy Study of 27 Cases. Human Pathology, 27, 766-773. http://dx.doi.org/10.1016/S0046-8177(96)90447-5

[26] Brosius, F.C., Waller, B.F. and Roberts, W.C. (1981) Radiation Heart Disease: Analysis of 16 Young (Aged 15 to 33 Years) Necropsy Patients Who Received over 3,500 Rads to the Heart. The American Journal of Medicine, 70, 519530. http://dx.doi.org/10.1016/0002-9343(81)90574-X 
[27] Fajardo, L.F. and Stewart, J.R. (1973) Pathogenesis of Radiation-Induced Myocardial Fibrosis. Laboratory Investigation, 29, 244-257.

[28] Domoto, S., Niinami, H., Kimura, F. and Nasuno, A. (2014) Clinical Images of Radiation-Induced Heart Disease. European Heart Journal, 35, 2196. http://dx.doi.org/10.1093/eurheartj/ehu145

[29] Santoro, F., Ieva, R., Lupo, P., Pellegrino, P.L., Correale, M., DiBiase, M. and Brunetti, N.D. (2012) Late Calcification of the Mitral-Aortic Junction Causing Transient Complete Atrio-Ventricular Block after Mediastinal Radiation of Hodgkin Lymphoma: Multimodal Visualization. International Journal of Cardiology, 155, e49-e50. http://dx.doi.org/10.1016/j.ijcard.2011.07.070

[30] Trapani, G., Quartuccio, S., Dalbeni, A., Stellitano, A., Paunovic, N. and Imbalzano, E. (2014) Late Radiation-Induced Cardiac Conduction System Abnormalities. International Journal of Cardiology, 173, e40-e41. http://dx.doi.org/10.1016/j.ijcard.2014.03.125

[31] Tamura, A, Takahara, Y., Mogi, K. and Katsumata, M. (2007) Radiation-Induced Valvular Disease in the Logical Consequence of Irradiation. Gen Thoracic and Cardiovascular Surgery, 55, 53-56. http://dx.doi.org/10.1007/s11748-006-0070-x

\section{Submit or recommend next manuscript to SCIRP and we will provide best service for you:}

Accepting pre-submission inquiries through Email, Facebook, Linkedin, Twitter, etc A wide selection of journals (inclusive of 9 subjects, more than 200 journals)

Providing a 24-hour high-quality service

User-friendly online submission system

Fair and swift peer-review system

Efficient typesetting and proofreading procedure

Display of the result of downloads and visits, as well as the number of cited articles

Maximum dissemination of your research work

Submit your manuscript at: http://papersubmission.scirp.org/ 